\title{
New promising antimicrobial material based on thermoplastic polyurethane modified with polymeric biocide polyhexamethylene guanidine hydrochloride
}

\author{
Sergiy Rogalsky ${ }^{\mathrm{a}, *}$, Jean-François Bardeau ${ }^{\mathrm{b}}$, Lyudmila Lyoshina ${ }^{\mathrm{c}}$, Oksana Tarasyuk ${ }^{\mathrm{a}}$, \\ Olga Bulko $^{c}$, Oleg Dzhuzha ${ }^{a}$, Tetiana Cherniavska ${ }^{\mathrm{d}}$, Valeriy Kremenitsky ${ }^{\mathrm{e}}$, Larisa Kobrina ${ }^{\mathrm{f}}$, \\ Sergii Riabov ${ }^{\mathrm{f}}$
}

${ }^{a}$ V. P. Kukhar Institute of Bioorganic Chemistry and Petrochemistry, National Academy of Science of Ukraine, 50, Kharkivske Shose, Kyiv, 02160, Ukraine

${ }^{\mathrm{b}}$ Institut des Molécules et Matériaux Du Mans, UMR CNRS 6283, Le Mans Université, Avenue Olivier Messiaen, 72085, Le Mans Cedex 9, France

${ }^{\mathrm{c}}$ Institute of Cell Biology and Genetic Engineering, National Academy of Science of Ukraine, 148 Academika Zabolotnoho Str., Kyiv, 03143, Ukraine

${ }^{\mathrm{d}}$ Chuiko Institute of Surface Chemistry, National Academy of Science of Ukraine, 17, General Naumov Str., Kyiv, 03164, Ukraine

e Technical Center, National Academy of Sciences of Ukraine, 13, Pokrovska Str., Kyiv, 04070, Ukraine

${ }^{\mathrm{f}}$ Institute of Macromolecular Chemistry, National Academy of Sciences of Ukraine, 48, Kharkivske Shose, Kyiv, 02160, Ukraine

\section{A R T I C L E I N F O}

\section{Keywords:}

Polyurethane

Antimicrobial

Polymeric biocide

Thermal properties

Controlled release

\begin{abstract}
A B S T R A C T
New antimicrobial polymer composite based on commercial polyurethane (PU) Laripur ${ }^{\circledR L P R 9020}$ and polymeric biocide polyhexamethylene guanidine hydrochloride (PHMG-Cl) has been prepared by solvent casting method. Modified PU films containing from 1 to $4 \mathrm{wt} \%$ of PHMG-Cl were characterized in terms of mechanical, thermal and surface properties, biocide release behavior, as well as antibacterial activity against Gram-negative (Escherichia coli) and Gram-positive (Bacillus subtilis) bacterial strains. The results of mechanical testing indicate that the introduction of PHMG-Cl did not cause noticeable changes in the tensile strength of PU films, but improved their elasticity by at least 20-30\%. The surface of PU/PHMG-Cl films was found to possess significantly higher hydrophobicity than neat polymer that is manifested in sharply increased water contact angle value from $72^{\circ}$ for neat PU to $95^{\circ}$ for PU/PHMG-Cl (2\%). According to thermogravimetric analysis data, PU/PHMG-Cl composites are thermally stable to at least $300{ }^{\circ} \mathrm{C}$ which indicate their availability for melt processing by common methods. The results of differential scanning calorimetry showed reduction of both glass transition and melting temperatures of PU by more than $7{ }^{\circ} \mathrm{C}$ when contained only $1 \%$ of PHMG-Cl.

Gradual release of polymeric biocide from modified PU films into water has been detected spectrophotometrically. The total biocide release ratio was found to be in the range from $29 \%$ to $48 \%$ after 50 hours immersion, depending on its content in polymer composite. PU/PHMG-Cl films showed much lower leaching rate into physiological saline solution compared to pure water (from $10 \%$ to $21 \%$ after 50 hours), which may be caused by poor solubility of polymeric biocide in sodium chloride solutions.

The study of antibacterial activity of modified PU films using both disc agar diffusion and contact methods indicate high efficacy against tested microorganisms when contained $3 \%$ of polymeric biocide. So, this approach,
\end{abstract}

\footnotetext{
* Corresponding author.

E-mail addresses: sergey.rogalsky@gmail.com, rogalsky@bpci.kiev.ua (S. Rogalsky).
} 
based on the modification of PU resin with polymeric biocide PHMG-Cl, has been discussed in terms of potential medical applications when biocide release system or contact active material are necessary.

\section{Introduction}

Polyurethanes (PUs) are among the most versatile construction materials which are used everywhere in modern life. PUs are segmented polymers, containing soft segments that provides flexibility and a hard segments formed by diisocyanate and chain extender that ensures high tensile strength $[1,2]$. Thus, they can be divided into several different classes based on the desired material properties: rigid, flexible, thermoplastic, elastomers [1]. Common PUs applications include building insulation, car and household furnishing, manufacture of footwear, coatings, adhesives and sealants, as well as textiles. PUs are popular materials for various medical applications due to the unique combination of toughness and flexibility, good resistance to impact and abrasion, biocompatibility, as well as easy processability by common methods. Melt-processable, or thermoplastic polyurethanes (TPUs) are used extensively in medical devices, such as catheters, tissue adhesives, needle hubs, oxygen masks, gloves, medical tubing, hospital bedding, surgical drapes, as well as wound dressing materials [1-3]. The most frequent medical use of PUs is for short-period implants [1,4]. Thus, PU based central venous catheters (CVCs) are an important component of the rescue and treatment of critically ill patients. An important advantage of PU based catheters is their considerable softening on insertion into the body due to some extent hydrophilicity [4]. However, medical implants are convenient surface for microbial growth, both the short-term devices (urinary catheters) and the long-term implants (artificial joints). Clinical trials on PU based internal medical devices showed that the microbial biofilm formation causes enzymatic biodegradation of the material $[4,5]$. Moreover, the resulting biofilms cause chronic infections because surface-associated microorganisms exhibit an increased tolerance to both antimicrobial agents and disinfectant chemicals [4-8]. In fact, most of the health care-associated infections were found to be medical-device related, and the common complication of CVC use is catheter-related blood stream infections [4,6,7].

Polyurethane wound-dressing films are utilized to make a coating that is impermeable to fluids and bacteria but allows moisture to permeate. PU foam dressings are able to handle large volumes of wound fluid, with different permeability characteristics $[9,10]$. Thus, bilayered PU wound dressing composed of microporous top layer and highly porous sponge-like sublayer are known to provide efficacy in preventing dehydration and bacterial penetration [9]. However, pathogenic microbial flora, especially in chronic wounds or surgical wounds, can lead to infection and sepsis, as well as excessive inflammation $[4,11]$. These complications most often lead to delayed healing, extended hospital stay and increased costs.

The introduction of antimicrobial agents into medical devices is considered the most efficient approach to prevent the growth of biofilms on their surface. A wide variety of organic and inorganic biocides is available, whether synthetic or nature-inspired [12-16]. Inorganic nanoparticles (titanium dioxide, zinc oxide, copper, silver) are widely employed as antimicrobial additives to various medical polymers, including PUs [4,16-20]. Silver in different forms (metallic or salt) is used as typical biocide for control of colonization of medical devices and dressing materials $[4,13,14]$. Silver ions can be released from the polymer matrix into the wound fluid or exudate and act against a wide spectrum of pathogens such as gram-negative and gram-positive bacteria, yeast and viruses. Because of this, silver-containing foam dressings have been commonly used for healing wounds, including burns, diabetic ulcers, and surgical wounds [21,22]. Silver-based biocides are nevertheless relatively expensive and in the case of nanoparticles it is necessary to implement complicated processes to disperse them homogeneously in the polymer matrix [19]. Moreover, the cellular toxicity of silver ions has also been reported in several studies as serious side-effect $[4,16,21,23]$ and it should also be noted that some bacterial strains are resistant to silver $[4,24,25]$.

Common approaches to impart antimicrobial activity to CVCs involved impregnation of materials with systemic antibiotics such as minocycline/rifampicin, miconazole/rifampicin, benzalkonium chloride, or with antiseptics such as synergistic combination of silver sulfadiazine/chlorhexidine $[4,26,27]$. The functionalization of medical devices with the said biocides can be time consuming and costly when it requires additional manufacturing steps and tight processing conditions to achieve uniformity. With surface functionalization, there is always the risk that the coatings have a reduced efficacy due to a lower density of antimicrobial molecules [4] and therefore contribute to increasing the tolerance of bacteria to antibiotics.

Povidone-iodine, or PVP-iodine is a labile complex of elemental iodine with polyvinyl pyrrolidone (PVP), which serves as sustained released reservoir of iodine [28]. PVP-iodine has demonstrated many benefits for wound healing due to its high activity against a broad spectrum of pathogenic microorganisms, and minimal cytotoxicity to host cells [28-30]. PU foam dressing materials containing PVP-iodine can be fabricated by one step bulk polymerization from a reactionary mixture involving polyglycol, diisocyanate and solid particles of PVP-iodine [31]. Recent studies have shown that new commercial PU foam dressing Betafoam impregnated with $3 \%$ of povidone-iodine was the most effective dressing in terms of wound healing and re-epithelialization compared to various silver-containing foams and gauze [32,33]. However, several studies reported the cases of povidone-iodide-induced burn that occurs when the substance was not allowed to dry [34]. Moreover, skin antisepsis with common cationic biocide chlorhexidine and alcohol solutions has demonstrated superiority to povidone-iodine in a variety of surgical interventions [35].

Nowadays, polymeric biocides comprising guanidinium cations in polymer backbone such as polyhexamethylene biguanide hydrochloride (PHMB-Cl) and polyhexamethylene guanidine hydrochloride (PHMG$\mathrm{Cl}$ ) are being considered as valuable and cheap alternatives to common inorganic antimicrobial agents since they demonstrated high efficacy in killing antibiotic-resistant bacteria and fungi, as well as low cytotoxicity [36-40]. The above cationic polymers are already widely used as effective disinfectants in cooling systems, swimming pools and hospitals, in personal hygiene products, as well as in food industry [36,38,39,41]. The preparation of PU/PHMB-Cl electrospun nanofibre membranes with polymeric biocide content $5-35 \%$ has been reported [42]. The membranes displayed burst release of PHMB-Cl into PBS solution during the first hour followed by a gradual release over 120 hours. PU films containing 5-15\% PHMB-Cl displayed superior antimicrobial activity, as well as minimal human cell toxicity confirming their use as wound dressing material [42].

Another polymeric biocide, PHMG-Cl has broad range of antimicrobial activity, being however much cheaper than PHMB-Cl due to simple one-step synthesis [41]. Recent studies have also shown that PHMG-Cl possesses pronounced anti-inflammatory and wound healing properties and therefore may be used for the treatment of chronic wounds and thermal burns [43]. Thus, PHMG-Cl based composite effectively reduced the level of proinflammatory and increased the level of pro-inflammatory cytokines, as well as normalized the oxidative-antioxidant homeostasis by normalizing the content of markers of free radical oxidation to accelerate the treatment of thermal burns. The antioxidant activity of this polymeric biocide has also been established in Ref. [44].

The acute toxicity studies on rats showed that the median lethal dose $\left(\mathrm{LD}_{50}\right)$ for PHMG-Cl is significantly higher $(600 \mathrm{mg} / \mathrm{kg})$ [45] than for 
PHMB-Cl (25.6 mg/kg) [46]. In other study, results of acute oral toxicity showed that PHMG-Cl at $5 \%$ presents a lethal dose $50 \%$ greater than the $2000 \mathrm{mg} / \mathrm{kg}$ [47]. From a practical point of view, PHMG-Cl seems very promising antimicrobial additive for thermoplastic PUs. Indeed, in contrast to PHMB-Cl, which has thermal decomposition point of 205-210 ${ }^{\circ} \mathrm{C}$ without melting [48,49], PHMG-Cl has low melting point of $135-140{ }^{\circ} \mathrm{C}$ and is thermally stable up to $313^{\circ} \mathrm{C}$ [50]. Such properties make it convenient for joint melt processing with TPU resins by common methods. However, the use of PHMG-Cl as an external additive for bulk modification of TPUs has not yet been reported. An amine terminated PHMG-Cl was prepared and used as curing agent of different epoxy-terminated polyurethane prepolymers. Such internally modified PU dressing membranes showed pronounced contact killing mechanism of antimicrobial activity, as well as excellent cytocompatibility against fibroplast cells [51].

So, in this study, commercial TPU was modified with low content of polymeric biocide PHMG-Cl (1-4 wt $\%$ ) in order to develop new promising antimicrobial material which has biocide releasing properties. The impact of PHMG-Cl additive on mechanical, surface and thermophysical properties, as well as antibacterial activity of PU, has been studied.

\section{Materials and methods}

\subsection{Synthesis of polymeric biocide $P H M G-C l$}

PHMG-Cl was synthesized by melt polycondensation of guanidine hydrochloride (98\%, Applichem) and hexamethylenediamine (98\%, Sigma-Aldrich), according to the method described in Ref. [50] (Scheme 1).

The mixture of guanidine hydrochloride $(20 \mathrm{~g}, 0.21 \mathrm{~mol})$ and hexamethylenediamine $(23.1 \mathrm{~g}, 0.2 \mathrm{~mol})$ was put into a round-bottomed flask $(500 \mathrm{ml})$ equipped with a mechanical stirrer. At first, the mixture was heated to $100^{\circ} \mathrm{C}$ and the melt was stirred for $4 \mathrm{~h}$ at this temperature. Further, the reaction was carried out for $4 \mathrm{~h}$ at $130-140{ }^{\circ} \mathrm{C}$ and $4 \mathrm{~h}$ at $180^{\circ} \mathrm{C}$ to obtain highly viscous melt. The vitreous solid of PHMG-Cl was obtained after cooling to room temperature. It was dissolved in water $(200 \mathrm{ml})$, filtered and precipitated by addition of saturated water solution of sodium chloride $(100 \mathrm{ml})$. The polymer was isolated by decantation of water solution, dried at $140{ }^{\circ} \mathrm{C}$ for $24 \mathrm{~h}$ and powdered in porcelain mortar. It has melting point of $136-138^{\circ} \mathrm{C}$. Intrinsic viscosity was $0.09 \mathrm{dl} / \mathrm{g}$ for PHMG-Cl solution in $0.1 \mathrm{~N} \mathrm{NaCl}$ at $25{ }^{\circ} \mathrm{C}$.

${ }^{1} \mathrm{H}$ NMR (400 MHz, DMSO-D 6 ): $\delta=1.32\left(\mathrm{~m}, 4 \mathrm{H}, \mathrm{CH}_{2}\right), 1.47(\mathrm{~m}, 4 \mathrm{H}$, $\mathrm{N}-\mathrm{CH}_{2} \mathrm{CH}_{2}$ ), 3.16 (m, 4H, N-CH $\mathrm{CH}_{2}$ ), 7.1-8.1 (br s, 4H, NH).

Elemental analysis: $\left(\mathrm{C}_{7} \mathrm{H}_{16} \mathrm{~N}_{3} \mathrm{Cl}\right) x(177.5) \mathrm{x}$ : found (\%): C 46.9, $\mathrm{H} 9.4$, N 24.0, Cl 20.5; calculated (\%): C 47.3, H 9.0, N 23.6, Cl 20.0.

\subsection{Preparation of PHMG-Cl modified PU films}

Thermoplastic adipate ester polyurethane Laripur ${ }^{\circledR L P R 9020 ~ w a s ~}$ purchased from COIM S.p.A. (Italy). $1 \mathrm{~g}$ of polymer was dissolved in 15 $\mathrm{ml}$ of $\mathrm{N}, \mathrm{N}$-dimethylformamide (Merck). PHMG-Cl was dissolved in ethanol $(10 \mathrm{wt} \%)$ and added to the PU solution in concentrations from 1 to $4 \mathrm{wt} \%$ in a composite and the mixture was stirred for $2 \mathrm{~h}$ at $50{ }^{\circ} \mathrm{C}$. The solutions were casted onto glass substrates and kept at $60{ }^{\circ} \mathrm{C}$ for $24 \mathrm{~h}$ to form polymeric films. They were dried in vacuum $5 \mathrm{mbar}$ at $50{ }^{\circ} \mathrm{C}$ for 24 h. The prepared films were about $150 \mu \mathrm{m}$ thick.

\subsection{Characterization of PU/PHMG-Cl composites}

In order to evaluate physicochemical interaction between PU and PHMG-Cl, the samples were first placed on the Platinum diamond ATR module and IR spectra were recorded using a Bruker Vertex-70V FTIR spectrometer (all Bruker Optics Inc., Ettlingen, Germany) equipped with a L-alanine-doped deuterated triglycine sulfate (DLaDTGS) detector. Spectra were acquired with a resolution of $2 \mathrm{~cm}^{-1}$ in the spectral region from 400 to $4000 \mathrm{~cm}^{-1}$ as the co-addition of 30 scans. Acquisition of these spectra has been done with the Bruker OPUS software (version 6.5).

Mechanical testing of the polyurethane samples was performed using P-50 universal tensile testing machine (Milaform, Russia) at a deformation rate of $10 \mathrm{~mm} / \mathrm{min}$. The obtained films were cut into specimens with the size of $40 \times 10 \times 0.15 \mathrm{~mm}$. An average value (with standard deviation) for the tensile strength was obtained from three samples of each film.

Static contact angle measurements were performed using a Drop Shape Analyzer DSA25E (Krüss, Germany) by the sessile drop method. The contact angle values were estimated, using CAM software, as the tangent normal to the water drop $(3 \mathrm{ml})$ at the intersection between the sessile drop and the polymer surface. All reported contact angles are the average of at least five measurements taken at different locations on the polymer surface.

The 3D surface scans of the samples were undertaken using the confocal white light optical imaging S-NEOX profiler (Sensofar-Tech S. L., Barcelona, Spain). The $850 \times 709 \mu \mathrm{m}^{2}$ area were collected using a 20 $\mathrm{X}$ EPI Nikon objective ( 0.45 numerical aperture). The data were analyzed by the open-source Gwyddion software (version 2.48). The average roughness $\mathrm{Sa}$, describing the difference in height of each point compared to the arithmetical mean of the surface, and the root mean square roughness $\mathrm{Sq}$, describing the root mean square average of height deviations taken from the mean data plane, were evaluated for each surface three times over the complete 3D surface respectively.

The scanning electron microscopy (SEM) images were obtained using a JSM-6490L V microscope (JEOL, Tokyo, Japan) equipped with an Oxford Instruments INCA 350 energy-dispersive X-ray spectroscopy (EDS) system allowing local quantitative elemental microanalysis of polymer surface. The samples were observed, after a platinum sputtering treatment, under an accelerating voltage of $20 \mathrm{kV}$. SEM images were acquired in secondary electron imaging (SEI) at different magnification of 2000X and 10000X. The lithium-drifted silicon $\mathrm{Si}(\mathrm{Li})$ detector is equipped with a thin beryllium window which allows oxygen to be revealed and quantified with good precision. However, the EDS detector cannot quantify with accuracy light elements, like carbon, and only gives relative analyzes.

Thermal gravimetric analysis (TGA) data were obtained using a TGA Q500 (TA Instruments). About $10 \mathrm{mg}$ of each sample was heated from $30{ }^{\circ} \mathrm{C}$ to $700{ }^{\circ} \mathrm{C}$ with a heating rate of $10{ }^{\circ} \mathrm{C} / \mathrm{min}$ under an air atmosphere.

Differential scanning calorimetry (DSC) measurements were performed using DSC Q2000 TA Instrument analyzer. The heating process was conducted from -90 to $150{ }^{\circ} \mathrm{C}$ at $20^{\circ} \mathrm{C} / \mathrm{min}$.

The release of PHMG-Cl from the PU film was investigated by UV-visible spectrophotometric analysis using a Jenway 6850 spectrometer (Great Britain). The calibrating graph was obtained by measuring the absorbance of PHMG-Cl aqueous solutions in a concentration range of $1.5 \cdot 10^{-5}-1.5 \cdot 10^{-4} \mathrm{~mol} / \mathrm{l}$ at $194 \mathrm{~nm}$ (water) and 204

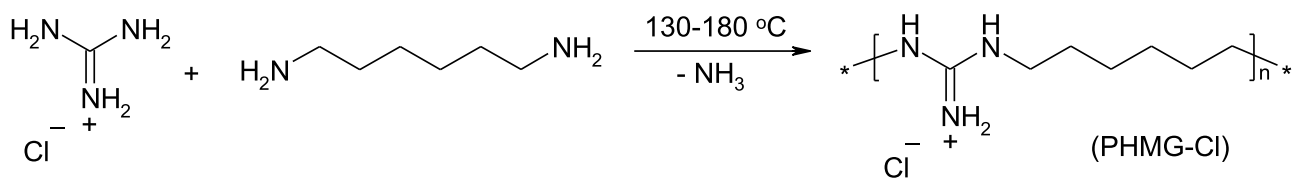

Scheme 1. Synthesis of polymeric biocide PHMG-Cl. 
$\mathrm{nm}(0.9 \% \mathrm{NaCl})$. For the evaluation of the leaching rate of polymeric biocide, $2 \mathrm{~g}$ of modified PU/PHMG films were placed into a closed 11 conical flask containing 11 of deionized water or $0.9 \%$ water solution of $\mathrm{NaCl}$. The samples were kept at $22{ }^{\circ} \mathrm{C}$ at constant stirring. $3 \mathrm{ml}$ of each solution was taken periodically and analyzed by measuring the absorbance at mentioned wavelength to determine the concentration of the released biocide. The biocide release ratio was determined as the percentage of PHMG-Cl released into the solution from its total quantity in the film. Each measurement has been repeated three times.

\subsection{Antibacterial activity tests}

Standard gram-negative Escherichia coli strain GM 2163 and grampositive Bacillus subtilis strain 168 were used to test antimicrobial activity of PU/PHMG-Cl films. The overnight culture was cultivated at 37 ${ }^{\circ} \mathrm{C}$ in $5 \mathrm{ml}$ of Luria-Bertani (LB) broth (composition per litre: $5 \mathrm{~g}$ yeast extract, $10 \mathrm{~g}$ tryptone, $10 \mathrm{~g} \mathrm{NaCl}$ (pH 7.5)) sterilized by autoclaving on wet cycle $20 \mathrm{~min}$ at $15 \mathrm{psi}$ to a concentration of $1.5 \cdot 10^{8}$ cell forming units (CFU) per $\mathrm{ml}$ (determined by measuring optical density at 540 $\mathrm{nm})$.

The antibacterial activity of PU/PHMG-Cl films was studied by both standard agar disc diffusion test [52] and the ISO 22196:2007 method [53] for determining the antimicrobial activity on material surfaces (contact method). Polyurethane films were cut into $10 \mathrm{~mm}$ diameter discs and sterilized by immersion into $70 \%$ water ethanol followed by ultraviolet irradiation for $30 \mathrm{~min}$ on each side.

\subsubsection{Agar disc diffusion test (diffusion method)}

The overnight bacterial culture $(100 \mu \mathrm{l})$ was added into $200 \mathrm{ml}$ conical flask containing $50 \mathrm{ml}$ of LB agar followed by shaking (140 rpm) at $37^{\circ} \mathrm{C}$ for $20 \mathrm{~h}$ to produce end concentration of $1.5 \cdot 10^{8} \mathrm{CFU} / \mathrm{ml}$ which was controlled by adjusting the turbidity of bacterial suspension to 0.5 McFarland standard. The bacterial culture was evenly poured onto plates with LB agar with the help of sterile cotton swab. The sterile polymer disc was placed on the culture lawn in the centre of the plate. Clear zone of inhibition (in $\mathrm{mm}$ ) formed around the disc was measured after $24 \mathrm{~h}$ incubation period at $37{ }^{\circ} \mathrm{C}$. The measurements were performed in triplicate for each polymer film.

The normalized width of the antimicrobial "halo" ( $n w_{\text {halo }}$ ) for each disc was determined according to Ref. [54] by using equation:

$n w_{\text {halo }}=\left[\left(\mathrm{d}_{\mathrm{iz}}-\mathrm{d}\right) / 2\right] / \mathrm{d}$, where $\mathrm{d}_{\mathrm{iz}}$ - the diameter of the inhibition zone, $\mathrm{d}$ - the disc diameter. An average value from three replicates was determined.

\subsubsection{Measurement of antimicrobial activity on material surface (contact method)}

Each polymer film was placed in a sterile Eppendorf in which $1 \mathrm{ml}$ of bacterial suspension was added (initial colonies concentration $10^{6} \mathrm{CFU}$ / $\mathrm{ml}$ ). The samples were incubated for $24 \mathrm{~h}$ at $37^{\circ} \mathrm{C}$. The bacterial culture in each Eppendorf was diluted 10 times ( $100 \mu \mathrm{l}$ of the suspension, $900 \mu \mathrm{l}$ of the LB agar). Each sample $(100 \mu \mathrm{l})$ was distributed on a plate containing agar LB medium. The plates were incubated for $24 \mathrm{~h}$ at $37{ }^{\circ} \mathrm{C}$. The number of viable microorganisms was determined according to Ref. [53] using the following equation:

$\mathrm{N}=\mathrm{C} \cdot \mathrm{D} / \mathrm{A}$, where $\mathrm{N}$ is the number of viable microorganisms recovered per $\mathrm{cm}^{2}$ per test specimen, $\mathrm{C}$ is the plate count, $\mathrm{D}$ is the dilution factor, A is the surface area of the test specimen in $\mathrm{cm}^{2}$.

The loss of viability ( $\mathrm{LV}, \%)$ to reflect the inhibition of cell growth was determined by using the equation:

$\mathrm{LV}(\%)=[(\mathrm{C}-\mathrm{S}) / \mathrm{C}] \times 100 \%$, where $\mathrm{C}$ is the average number of viable microorganisms $(N)$ in $\mathrm{CFU} / \mathrm{ml} \cdot \mathrm{cm}^{2}$, recovered from the control specimens after $24 \mathrm{~h}$; $\mathrm{S}$ is the number of viable microorganisms $(N)$ in CFU/ $\mathrm{ml} \cdot \mathrm{cm}^{2}$, recovered from the test specimens after $24 \mathrm{~h}$ [54].

\section{Results and discussion}

\subsection{FTIR studies of PU/PHMG-Cl composites}

FT-IR measurements were carried out to verify the preparation of the composites by analyzing the specific peak positions. Fig. 1 shows the infrared spectra of PU, the composite PU/PHMG-Cl (4\%), and PHMG-Cl. For adipate ester PU, the assignment of the vibration modes was made on the basis of previous published work [55-57].

In Fig. 1a, the IR spectrum of PU presents a broad band at $3326 \mathrm{~cm}^{-1}$ and two main peaks located at 2942 and $2852 \mathrm{~cm}^{-1}$ commonly assigned to $\mathrm{N}-\mathrm{H}$ stretching mode and asymmetric and symmetric aliphatic $\mathrm{CH}_{2}$ stretching modes respectively. In Fig. 1b, the more intense peaks of PU at 1728 and $1700 \mathrm{~cm}^{-1}$ are attributed respectively to non-hydrogen bonded and hydrogen bonded urethane $\mathrm{C}=\mathrm{O}$ stretching vibrational modes. It is also admitted that the asymmetric and intense band centered around $1528 \mathrm{~cm}^{-1}$ is attributed to urethane $\mathrm{N}-\mathrm{H}$ bending $+\mathrm{C}-\mathrm{N}$ stretching mode, the band at $1220 \mathrm{~cm}^{-1}$ to urethane $\mathrm{C}-\mathrm{N}$ stretching mode and the bands at 1109 and $1078 \mathrm{~cm}^{-1}$ to aliphatic asymmetric and symmetric C-O-C stretching modes.

In Fig. 1a, the IR spectrum of PHMG-Cl presents very broad bands in the region 3050 to $3400 \mathrm{~cm}^{-1}$ (with maxima at approximately 3152 and $3254 \mathrm{~cm}^{-1}$ ) resulting of $\mathrm{NH}_{2}$ and $\mathrm{NH}$ stretching modes and two welldefined peaks at 2934 and $2857 \mathrm{~cm}^{-1}$ attributed directly to the asymmetric and symmetric stretching vibrations of the methylene groups, respectively [41]. The infrared spectrum presents also strong absorption bands between 1550 and $1700 \mathrm{~cm}^{-1}$, characteristic of both the $\mathrm{C}=\mathrm{N}$ stretching and the in-plane $\mathrm{NH}_{2}$ scissoring modes and the band at 1462 $\mathrm{cm}^{-1}$ to the bending vibrations of $\mathrm{CH}_{2}$ groups.

A comparison of the IR spectra of the neat PU film and the PU/ PHMG-Cl (4\%) composite reveals there is no evident difference between the intensity and the maximum positions of all characteristic bands (Fig. 1). Indeed, despite the polar structure of PHMG-Cl, IR analysis did not detect any strong physicochemical interaction between the guanidine salt moiety and urethane groups. This is probably due to a low content of polymeric biocide in the composite. Nevertheless, for the PU/PHMG-Cl (4\%) composite, the main noticeable changes concern the relative intensities of the $\mathrm{CH}_{2}$ and $\mathrm{NH}$ stretching vibration modes. The absorbance of the $\mathrm{NH}$ stretching mode decreases that may indicate hydrogen bonding with chloride ions. The absorbance of the $\mathrm{CH}_{2}$ stretching modes increases and note that the $\mathrm{CH}_{2}$ symmetric stretching vibrations are shifted from 2852 to $2858 \mathrm{~cm}^{-1}$. Moreover, the peak position of symmetric C-O-C stretching vibrations of PU aliphatic chains has also been changed from 1078 to $1070 \mathrm{~cm}^{-1}$. Overall, this may indicate weak intermolecular interaction between aliphatic chains of PHMG-Cl and PU (Scheme 2).

\subsection{Mechanical, surface and thermal properties of PU/PHMG-Cl composites}

According to the results of mechanical tests, the introduction of PHMG-Cl did not lead to noticeable changes in tensile strength of PU films (Table 1). At the same time, increased elasticity was observed for PU films containing $1 \%$ and $2 \%$ of PHMG-Cl (by at least $20-30 \%$ compared to neat polymer). However, further increase of PHMG-Cl content returned the elasticity to initial values comparable with neat PU (Table 1).

The results of static water contact angle measurements of PU films are summarized in Fig. 2. For all PU/PHMG-Cl composites, significantly increased hydrophobicity was detected compared to neat PU, with maximum contact angle value for PU/PHMG-Cl (2\%).

Fig. 3 shows SEM images of modified PU films. The presence of micropores with pore size around $1 \mu \mathrm{m}$ is observed on the surface of PU/ PHMG-Cl (2\%) films (Fig. 3, 2), whereas the surface of neat PU is mainly uniform (Fig. 3, 1). SEM images of PU/PHMG-Cl (4\%) showed the presence of a significant number of micropores with pore size around 

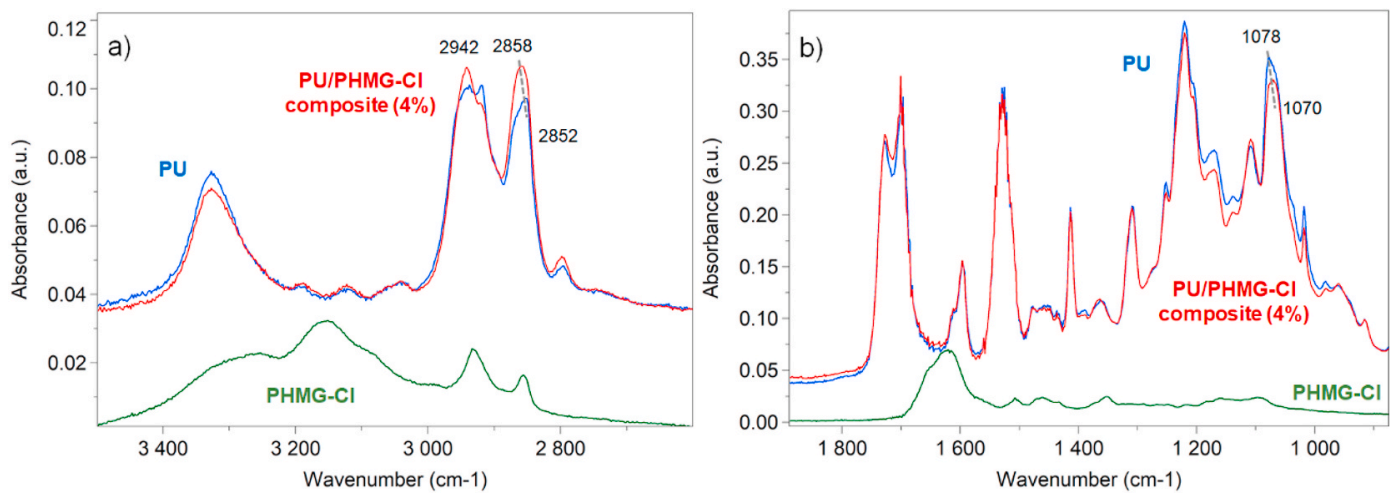

Fig. 1. Infrared spectra of PU, PU/PHMG-Cl (4\%) composite and PHMG-Cl.

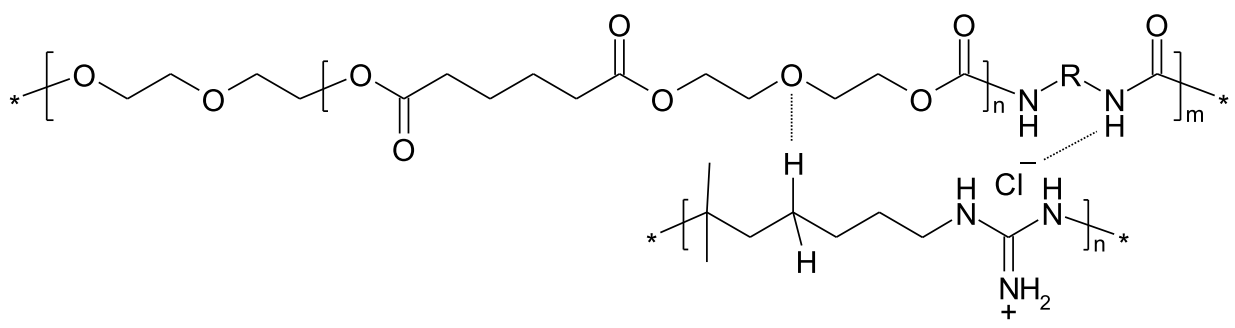<smiles>CC(C)(C)OCCOCCOC(=O)CCCCC(=O)OCCOCCOC(=O)NNPNC(=O)C(C)(C)C</smiles>

Scheme 2. Possible physicochemical interaction between PU and PHMG-Cl.

Table 1

Mechanical properties of PU/PHMG-Cl films.

\begin{tabular}{lll}
\hline Sample & Tensile strength, MPa & Elongation at break, \% \\
\hline PU control & $14.0 \pm 1.5$ & $524 \pm 10$ \\
PU/PHMG-Cl (1\%) & $14.5 \pm 1.2$ & $630 \pm 14$ \\
PU/PHMG-Cl (2\%) & $15.0 \pm 2.4$ & $701 \pm 18$ \\
PU/PHMG-Cl (3\%) & $15.5 \pm 2.8$ & $543 \pm 10$ \\
PU/PHMG-Cl (4\%) & $16.0 \pm 0.5$ & $495 \pm 12$ \\
\hline
\end{tabular}

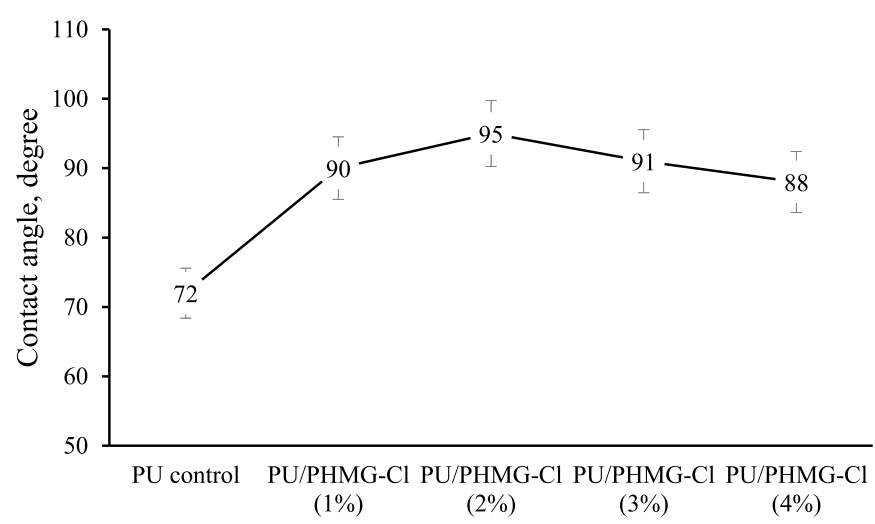

Fig. 2. Contact angle values for modified PU films.

$2 \mu \mathrm{m}$ (Fig. 3, 3). These observations are consistent with the averaged roughness values obtained from the $3 \mathrm{D}$ surface scans using the confocal white light optical imaging profiler (Fig. 4). Indeed, the roughness values Sa and Sq of PU/PHMG-Cl films (1\%) are similar to those found for neat PU, then increase by $0.2 \mu \mathrm{m}$ between $1 \%$ and 3\% PHMG-Cl and by $0.4 \mu \mathrm{m}$ between $3 \%$ and $4 \%$.

EDS microanalysis showed the presence of chlorine $(1.75 \pm 0.25 \%)$ in all areas of the surface of PU/PHMG-Cl (4\%) sample (Fig. 3, 3). Since the chlorine content in PHMG-Cl is $20 \mathrm{wt} \%$, PU/PHMG-Cl (4\%) composites should contain $0.8 \%$ of $\mathrm{Cl}$ in the volume. The excess chlorine content on the surface of PU films is obviously due to the orientation of hydrophilic ionic groups outward of the polymer matrix. The presence of hydrophilic polymeric biocide on the surface may thus explain the reduction of contact angle value reported in Fig. 2. Let us noticed that EDS measurements didn't detect any chlorine on the surface of PU/ PHMG-Cl films containing $1 \%$ and $2 \%$ of polymeric biocide (Fig. 3, 2). Therefore, the increase in the hydrophobicity of these PU/PHMG-Cl composite films (Fig. 2) is probably due to the physicochemical interactions of the polymeric biocide with polar groups of PU, thus reducing the wetting of the surface polymer with the water.

According to TGA data, neat PU has thermal decomposition point (5\% weight loss) $314{ }^{\circ} \mathrm{C}$ (Fig. 5a). This value is very similar to those for polymeric biocide PHMG-Cl which is thermally stable to at least $313{ }^{\circ} \mathrm{C}$ [50]. The thermo-oxidative degradation of neat PU takes place in successive decomposition steps occurring between 300 and $650{ }^{\circ} \mathrm{C}$ (Fig. 5a). The first one is related to the decomposition of the hard segments, whereas the second step is due to the composition of the soft segments [16]. The introduction of PHMG-Cl did not cause significant changes of thermal stability of PU (Fig. 5b). The results of TGA for PU/PHMG-Cl composites containing from 1 to $4 \mathrm{wt} \%$ of polymeric biocide are summarized in Table 2. From these data it can be supposed that PHMG-Cl is acceptable modifying additive for joint melt processing with PU resin.

According to DSC data, polymeric biocide PHMG-Cl has glass transition temperature $\left(T_{g}\right)$ of $6.3^{\circ} \mathrm{C}$ and melting point $\left(T_{m}\right)$ of $137^{\circ} \mathrm{C}$ (Fig. 6 , curve 1). Neat polyurethane melts at $134^{\circ} \mathrm{C}$ and has $T_{g}$ value of $-37.4{ }^{\circ} \mathrm{C}$ 

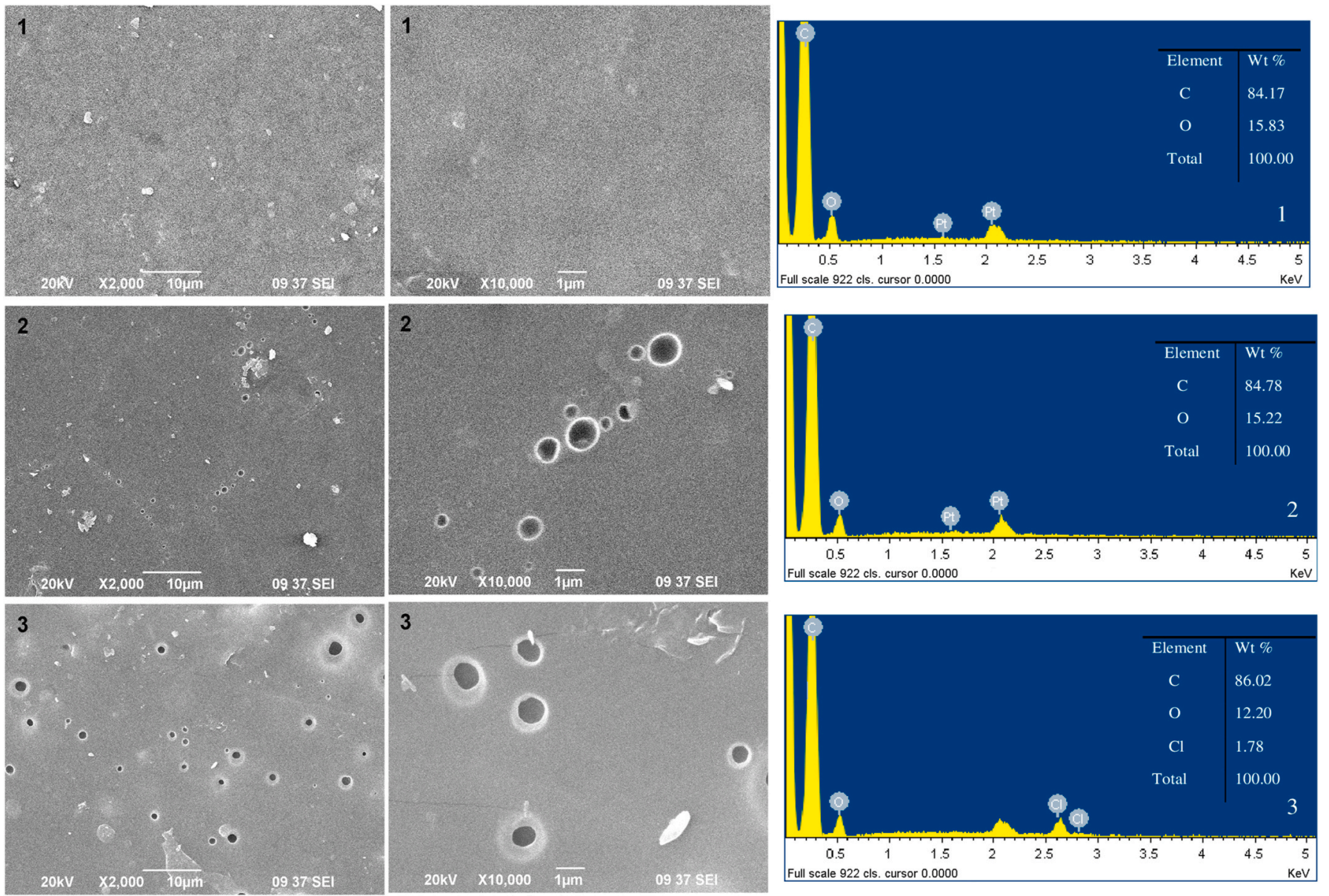

Fig. 3. SEM and EDS images of polymer films: 1 - PU, 2 - PU/PHMG-Cl (2\%), 3 - PU/PHMG-Cl (4\%)

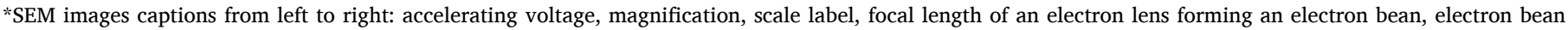
current in relative units, image acquisition mode (secondary electron imaging - SEI).

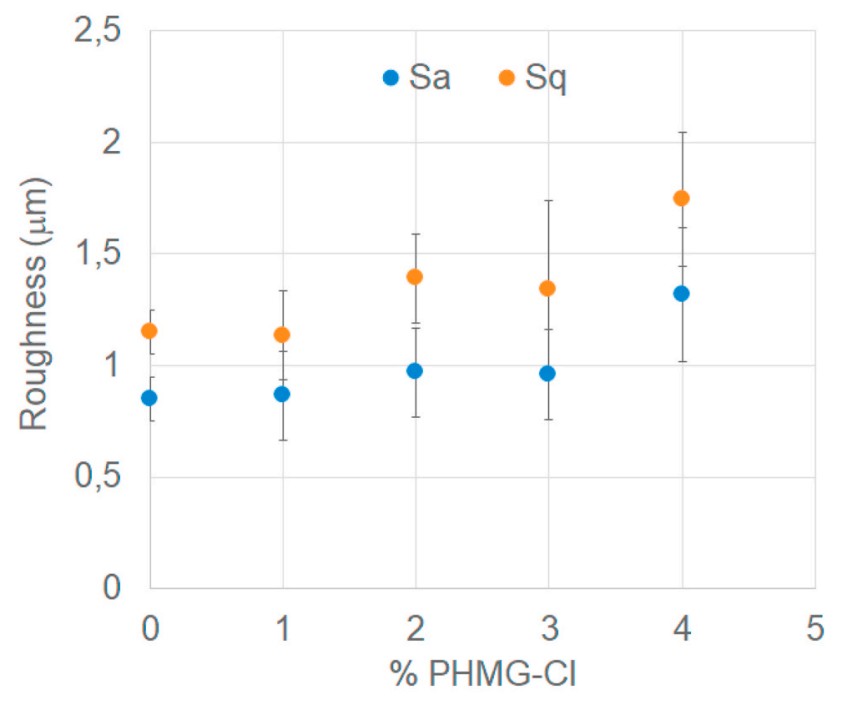

Fig. 4. Surface roughness of PU/PHMG-Cl films.

(Fig. 6, curve 2). For PU/PHMG-Cl composites, noticeable shift of both $T_{g}$ and $T_{m}$ to lower values was detected. Thus, introduction of $4 \%$ of PHMG-Cl into PU led to reduction of glass transition temperature of the polymer by $8.5^{\circ} \mathrm{C}$, as well as its melting temperature by $7{ }^{\circ} \mathrm{C}$ (Fig. 6 , curve 4). For lower PHMG-Cl content, similar decrease of $T_{g}$ and $T_{m}$ values were observed (Fig. 6, curve 3, Table 3). Overall, the obtained results indicate plasticizing effect of PHMG-Cl on PU that is confirmed by significantly increased elongation at break of PU/PHMG-Cl films (Table 1).

\subsection{Biocide release behavior of PU/PHMG-Cl films}

UV-visible absorption spectrum of PHMG-Cl in water solutions (Fig. 7, curve 1) presents a maximum peak at $192 \mathrm{~nm}$ that corresponds to the adsorption of $\mathrm{C}=\mathrm{N}$ groups [58]. In $0.9 \%$ saline solution, the maximum peak is shifted to $204 \mathrm{~nm}$ (Fig. 7, curve 2). The release properties of the films were tested by keeping PU/PHMG-Cl samples in contact with deionized water and saline solutions for $10 \mathrm{~h}$. Both solutions were analyzed by UV-Vis spectroscopy and the observation of maximum peaks around $192 \mathrm{~nm}$ and $204 \mathrm{~nm}$ for water and saline solution respectively confirms the release behavior of polymeric biocide into water from PU/PHMG-Cl films.

In order to determine the release properties of the film as function of PHMG-Cl content, we measured the absorbance at $192 \mathrm{~nm}$ as function of time and calculate the percentage of PHMG-Cl released into water from its total quantity in the film. For PU sample containing $1 \%$ of PHMG-Cl, fast biocide release (almost 16\%) was observed after $8 \mathrm{~h}$ followed by more gradual release reaching the value $29 \%$ after $50 \mathrm{~h}$ (Fig. 8, curve 1). For PU films with higher PHMG-Cl content (from 2 to 4\%), biocide release curves contain three distinct regions (Fig. 8, curves 2-4). The 

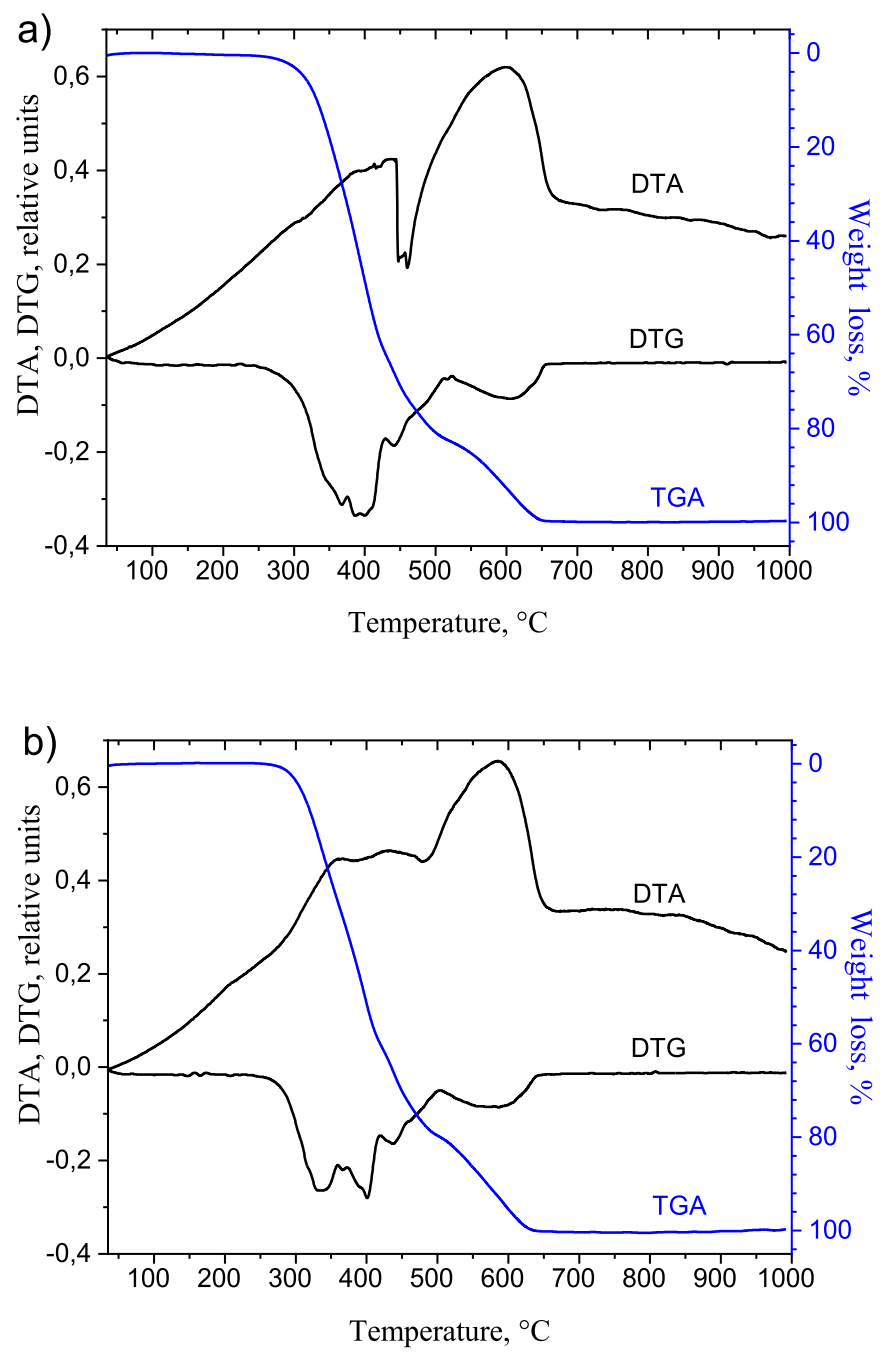

Fig. 5. TGA curves of PU (a) and composite PU/PHMG-Cl (4\%) (b).

Table 2

TGA data for modified PU samples.

\begin{tabular}{|c|c|c|c|c|}
\hline Sample & $\begin{array}{l}\mathrm{T}_{\Delta \mathrm{m}}=5 \% \\
{ }^{\circ} \mathrm{C}\end{array}$ & $\begin{array}{l}\mathrm{T}_{\Delta \mathrm{m}}=10 \% \\
{ }^{\circ} \mathrm{C}\end{array}$ & $\begin{array}{l}\mathrm{T}_{\Delta \mathrm{m}}=20 \% \\
{ }^{\circ} \mathrm{C}\end{array}$ & $\begin{array}{l}\mathrm{T}_{\Delta \mathrm{m}}=50 \% \\
{ }^{\circ} \mathrm{C}\end{array}$ \\
\hline PU control & 314 & 332 & 353 & 402 \\
\hline PHMG-Cl & 313 & 347 & 358 & 389 \\
\hline $\begin{array}{l}\text { PU/PHMG-Cl } \\
\text { (1\%) }\end{array}$ & 306 & 321 & 341 & 400 \\
\hline $\begin{array}{l}\text { PU/PHMG-Cl } \\
(2 \%)\end{array}$ & 305 & 320 & 340 & 397 \\
\hline $\begin{array}{l}\text { PU/PHMG-Cl } \\
(3 \%)\end{array}$ & 305 & 318 & 338 & 397 \\
\hline $\begin{array}{l}\text { PU/PHMG-Cl } \\
(4 \%)\end{array}$ & 303 & 317 & 337 & 395 \\
\hline
\end{tabular}

fastest releases of PHMG-Cl were observed during the first hour of immersion: $12.7 \%$ for PU samples with $2 \%$ biocide content (curve 2) and more than $22 \%$ for polymer films with 3 and $4 \%$ PHMG-Cl (curves 3, 4). From 2 to $8 \mathrm{~h}$ a fast biocide release for all these samples was also detected followed by more gradual constant release in the next stage. After $50 \mathrm{~h}$ immersion, PU films containing 2, 3 and 4\% of PHMG-Cl showed relatively similar biocide release ratio: $41.6 \%, 45.4 \%$ and 48.7\%, respectively (Fig. 8). Spectrophotometric control of PHMG-Cl release from PU films have shown that this process continued for at least 14 days reaching the release ratio of $57 \%$ for PU/PHMG-Cl (3\%) and 70\% for PU/PHMG-Cl (4\%) composites (not shown in Figure).

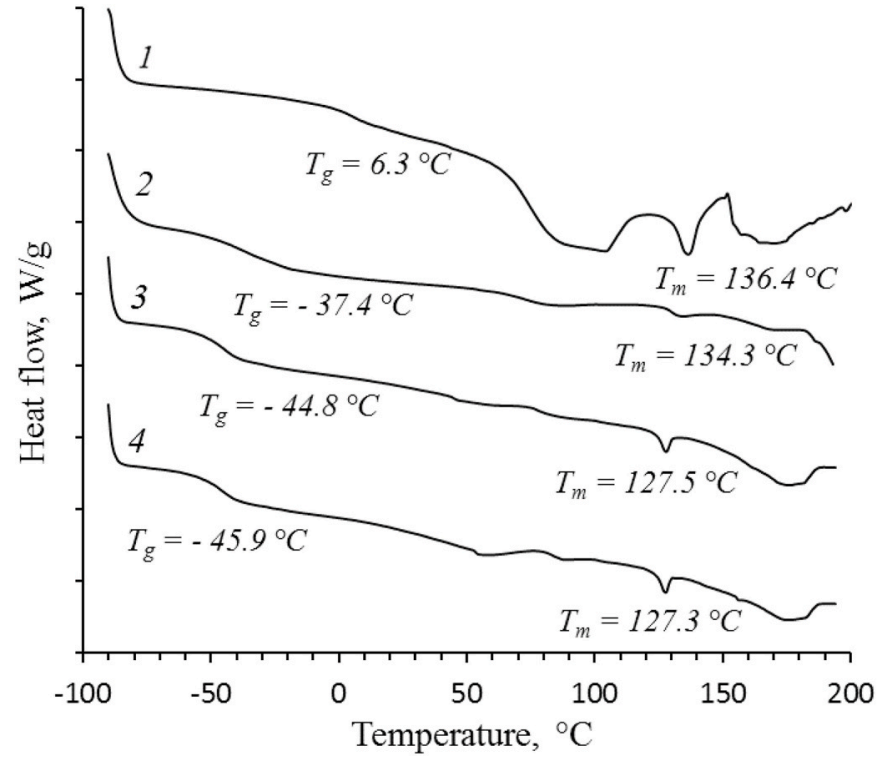

Fig. 6. DSC thermograms: 1 - PHMG-Cl, 2 - PU, 3 - PU/PHMG-Cl (1\%), 4 PU/PHMG-Cl (4\%)

Table 3

DSC data for modified PU samples.

\begin{tabular}{llll}
\hline Sample & $T_{g},{ }^{\circ} \mathrm{C}$ & $\Delta \mathrm{C}_{\mathrm{p}}, \mathrm{J} /\left(\mathrm{g} \cdot{ }^{\circ} \mathrm{C}\right)$ & $T_{m},{ }^{\circ} \mathrm{C}$ \\
\hline PU control & -37.4 & 0.26 & 134.3 \\
PHMG-Cl & 6.3 & 0.17 & 136.4 \\
PU/PHMG-Cl (1\%) & -44.8 & 0.23 & 127.5 \\
PU/PHMG-Cl (2\%) & -45.3 & 0.22 & 128.3 \\
PU/PHMG-Cl (3\%) & -45.2 & 0.24 & 127.7 \\
PU/PHMG-Cl (4\%) & -45.9 & 0.21 & 127.3 \\
\hline
\end{tabular}

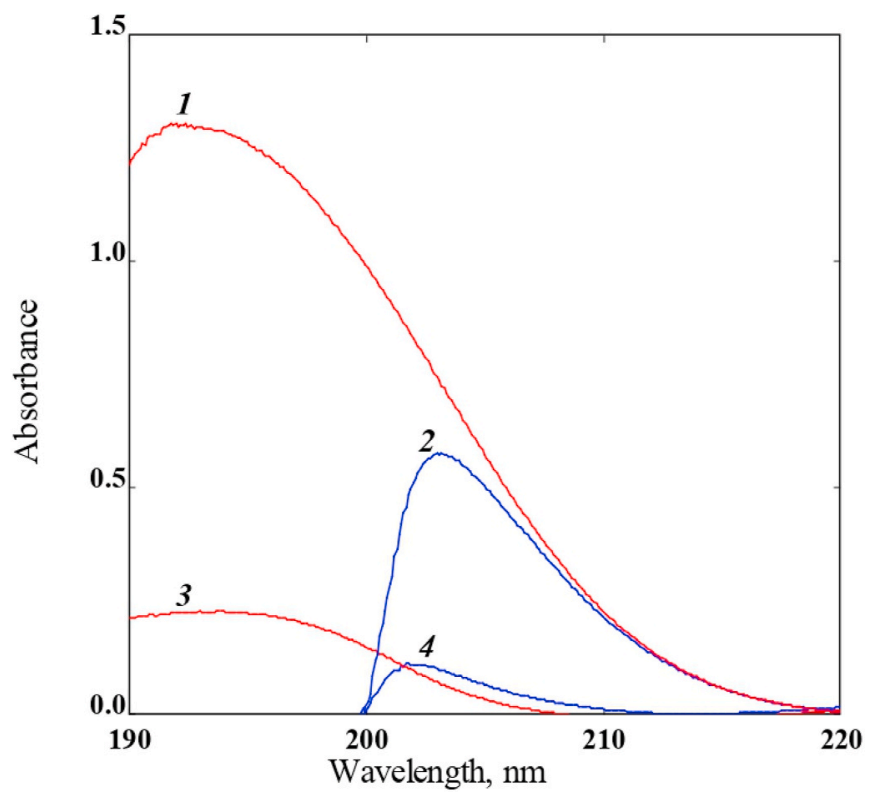

Fig. 7. UV-visible absorption spectra of PHMG-Cl: $1-\mathrm{C}=1.1 \cdot 10^{-4} \mathrm{~mol} / \mathrm{l}$ (water), $2-\mathrm{C}=1.1 \cdot 10^{-4} \mathrm{~mol} / 1$ ( $0.9 \%$ saline), 3 - water solution after $10 \mathrm{~h}$ contact with PU/PHMG-Cl (1\%) film, 4-0.9\% saline after 10 h contact with PU/ PHMG-Cl (1\%) film. 


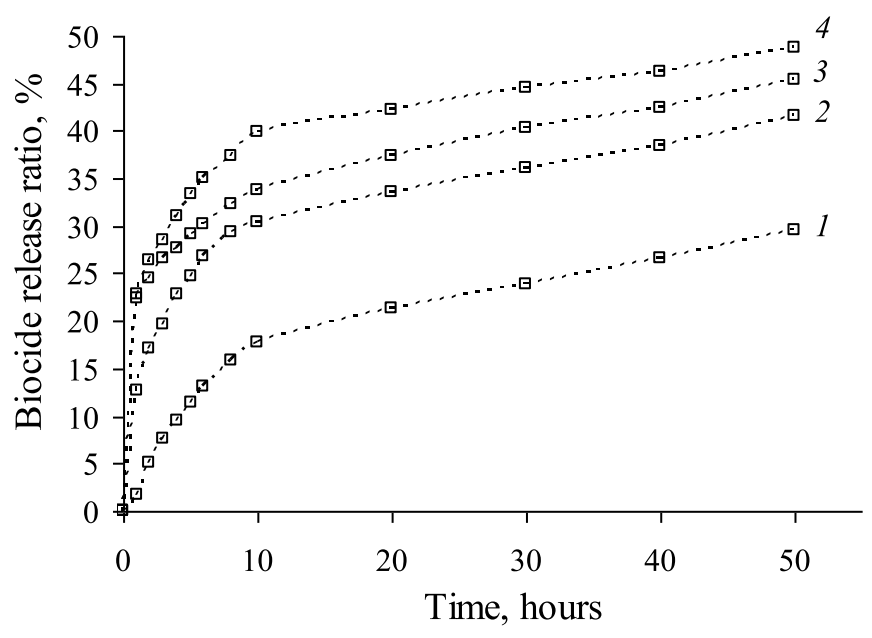

Fig. 8. The release behavior of polymeric biocide into water from PU/PHMG-Cl films containing 1\% (1), 2\% (2), 3\% (3) and 4\% (4) of PHMG-Cl.

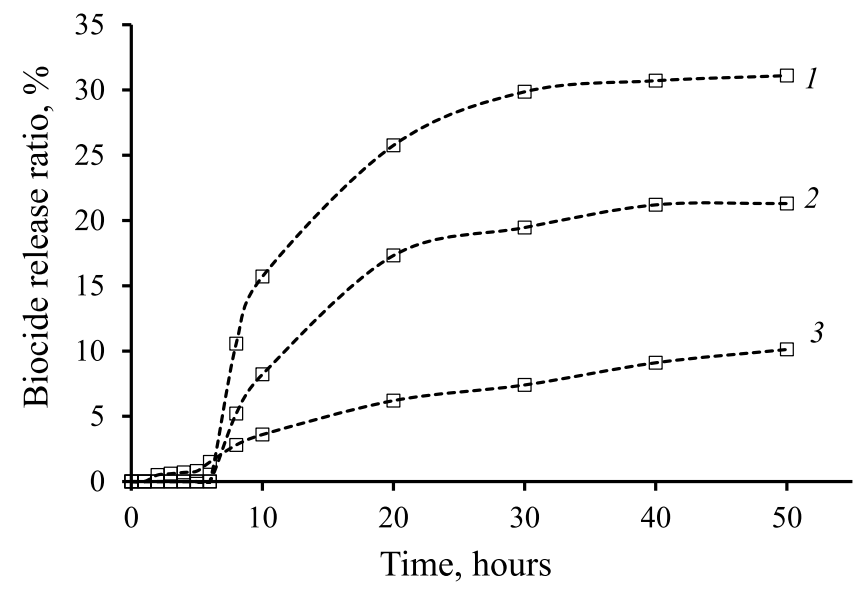

Fig. 9. The release behavior of polymeric biocide into $0.9 \%$ saline from PU/ PHMG-Cl films containing 1\% (1), 2\% (2) and 3\% (3) of PHMG-Cl.

Taking into account poor solubility of PHMG-Cl in sodium chloride water solutions [50], delayed release rate of polymeric biocide from PU films into physiological saline could be expected. Indeed, the analysis of biocide release curves for polymer films containing 1-3\% PHMG-Cl indicated the presence of induction period for at least $6 \mathrm{~h}$ (Fig. 9). For PU/PHMG-Cl (1\%) samples, a fast biocide release was observed over the next $4 \mathrm{~h}$ followed by more gradual release rate (Fig. 9, curve 1). However, the total percentage of PHMG-Cl release was found to be similar for both water and saline after $50 \mathrm{~h}, 29 \%$ and $31 \%$, respectively. For higher biocide content in PU films ( $2 \%$ and $3 \%$ ), much lower total percentage of its release was detected: $21.3 \%$ and $10.1 \%$, respectively, compared to pure water (Fig. 9, curves 2 and 3). At highest PHMG-Cl content in PU films of $4 \%$, biocide release behavior curve had similar view (not shown).

It should be noted that the prepared PU/PHMG-Cl composites showed similar biocide release profile as electrospun nanofibre PU/ PHMB membranes reported in Ref. [42]. Overall, the results of this study indicate that PU/PHMG-Cl composites may be efficient controlled biocide release systems and therefore are promising for use as medical dressings.

\subsection{Antibacterial activity of PU/PHMG-Cl films}

The antibacterial activity of PU/PHMG-Cl films was tested using disc diffusion assays (Fig. 10). Control PU films, as well as PU/PHMG-Cl

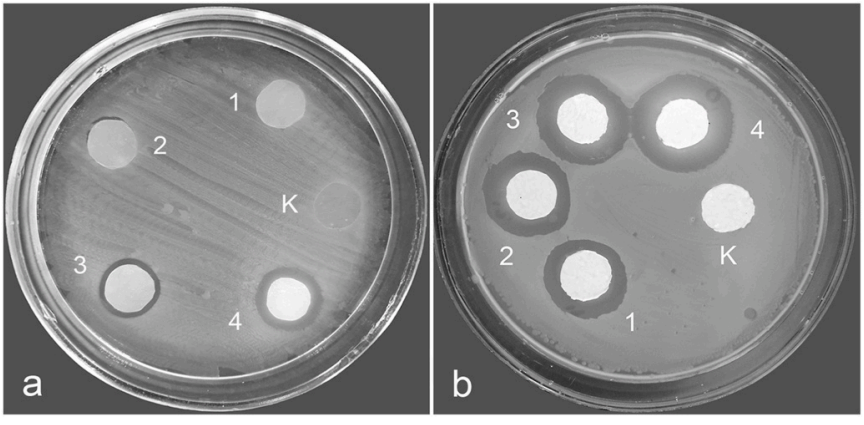

Fig. 10. PU discs on the surface of LB agar inoculated with E. coli (a) and B. subtilis (b) after $24 \mathrm{~h}$ incubation (Agar Disc Diffusion Test): $\mathrm{K}$ - neat PU (control), 1-4 - PU films containing from 1 to 4\% of PHMG-Cl, respectively.

composites containing $1 \%$ and $2 \%$ of polymeric biocide did not show detectable zones of inhibition of bacterial growth (E. coli) around sample discs (Fig. 10, a). The appearance of clear zone of inhibition was detected for PU/PHMG-Cl (3\%) sample, and this zone significantly increased for PU/PHMG-Cl (4\%) (Fig. 10). The obtained data indicate low antibacterial activity of modified PU films, probably caused by slow release of polymeric biocide into agar medium. Our data are in good agreement with those previously reported on antibacterial activity of PU/PHMB composite membranes [42]. Indeed, PU films containing from 5 to $15 \%$ of polymeric biocide PHMB-Cl showed small diameters of zones of inhibition (2-6 mm) in liquid $S$. aureus bacterial cultures [42]. Significant values of inhibition zone diameter above $10 \mathrm{~mm}$ were observed only for polymer films with much higher PHMB content (25-35\%).

In LB agar inoculated with B. subtilis, modified PU films form much larger inhibition halos even at lower PHMG-Cl content (Fig. 10, b, Table 4). This indicates higher sensitivity of gram-positive bacteria (B. subtilis) to PHMG-Cl, compared to gram-negative (E. coli).

The antibacterial activity of PU/PHMG-Cl films were also tested by contact method (Fig. 11 and Table 4). Significant reduction of bacterial colonies (E. coli) grown in agar medium after $24 \mathrm{~h}$ contact with polymer films was detected for PU/PHMG-Cl samples containing $2 \%$ of polymeric biocide (Fig. 11, b). Further increase of PHMG-Cl content to $3 \%$ led to total inhibition of bacterial growth (Fig. 11, c). Modified PU films were also found to have higher activity against gram-positive bacteria B. subtilis. Thus, total inhibition of test-culture was detected for PU/ PHMG-Cl (2\%) (not shown in Figure).

Overall, the obtained data indicate that PU/PHMG-Cl composites possess pronounced antibacterial activity at biocide content starting from $3 \%$ and combine properties of both biocide release system and contact active antimicrobial material. At lower PHMG-Cl content of $2 \%$, the antibacterial activity of modified PU films is probably realized mainly by contact active mechanism. It is worth noting that similar content (5 wt $\%$ ) of commonly used biocides such as silver nanoparticles and PHMB-Cl were required to inhibit the growth of common hospital pathogenic bacteria on the surface of PU based dressing materials [42, 59].

Table 4

Antibacterial activity of PU/PHMG-Cl composite films.

\begin{tabular}{llllll}
\hline \multirow{2}{*}{ Sample } & \multicolumn{2}{l}{$\mathrm{nw}$ halo } & & & \multicolumn{2}{l}{ LV, \% } & \\
\cline { 2 - 3 } & E.coli & B. subtilis & & E. coli & B. subtilis \\
\hline PU/PHMG-Cl (1\%) & 0 & 0.27 & 90 & 99 \\
PU/PHMG-Cl (2\%) & 0 & 0.33 & & 99.97 & 99.999 \\
PU/PHMG-Cl (3\%) & 0.11 & 0.38 & & 99.999 & - \\
PU/PHMG-Cl (4\%) & 0.28 & 0.44 & & - & - \\
\hline
\end{tabular}



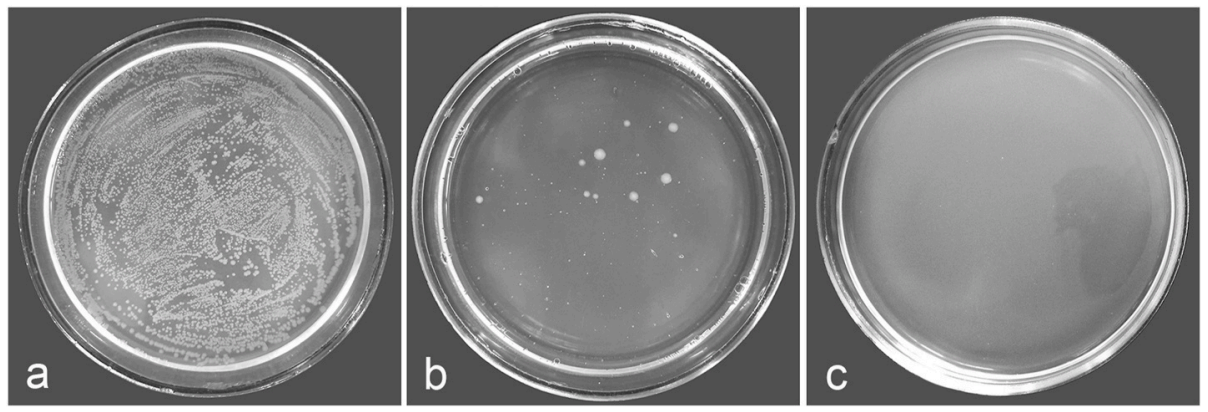

Fig. 11. Bacterial colonies (E. coli) grown on LB agar medium after $24 \mathrm{~h}$ contact with PU films (Antibacterial Contact Method): a - neat PU, b - PU/PHMG-Cl (2\%), c - PU/PHMG-Cl (3\%).

\section{Conclusion}

Commercial polyurethane Laripur®LPR9020 was blended with polymeric biocide PHMG-Cl using solvent casting method to prepare antibacterial polymer composites containing from 1 to $4 \mathrm{wt} \%$ of PHMG$\mathrm{Cl}$. The modified polymer films showed similar tensile strength and noticeably improved elasticity (by at least 20-30\%), compared to neat PU. The surface of PU/PHMG-Cl films was found to possess higher hydrophobicity than neat polymer that is manifested in significantly increased water contact angle values. This effect is probably caused by physicochemical interaction between polymeric biocide and PU which was detected by IR analysis. According to the results of TGA, PU/PHMG$\mathrm{Cl}$ composites have thermal decomposition points above $300{ }^{\circ} \mathrm{C}$ which are only slightly lower than those for pure polymer. The results of DSC measurements showed noticeable reduction of both glass transition temperature and melting temperature of PU (by more than $7{ }^{\circ} \mathrm{C}$ ) when contained only $1 \%$ of PHMG-Cl. However, further increase of additive content had little or no effect on thermophysical properties of PU which may indicate limited plasticizing effect of PHMG-Cl.

The results of spectrophotometric study showed gradual release of polymeric biocide from PU films into water for at least 14 days. At the first stage ( $8-10 \mathrm{~h}$ ) fast biocide release was detected for all PU/PHMG-Cl composites followed by more gradual stage. The total biocide release ratio was found to be from $29 \%$ to $48 \%$ after $50 \mathrm{~h}$ immersion, depending on its content in polymer composite. PU films containing $2 \%$ and $3 \%$ of PHMG-Cl showed much lower biocide release rate into physiological saline solution which may be caused by poor solubility of polymeric biocide in sodium chloride solutions. Thus, only $21 \%$ and $10 \%$ of PHMG$\mathrm{Cl}$ released from PU films after $50 \mathrm{~h}$ immersion in $0.9 \% \mathrm{NaCl}$ solution.

The results of microbiological study of modified PU films indicate their high antibacterial activity when contained $2 \%$ and $3 \%$ of polymeric biocide. The material can be considered both biocide release and contact active system. The latter (contact active) mechanism of antibacterial activity probably dominates, especially at low PHMG-Cl content of $2 \%$ and $3 \%$.

Thus, the modification of PU resin with polymeric biocide PHMG-Cl seems efficient approach to prepare new promising antimicrobial materials with controlled biocide release which may find different medical applications. Particularly, PU/PHMG-Cl composites can be used to fabricate dressings for healing of dermal or burn wounds, as well as surgical drapes, where local antimicrobial activity is required.

\section{CRediT authorship contribution statement}

Sergiy Rogalsky: synthesized polymeric biocide, analyzed data, and wrote the paper. Jean-François Bardeau: wrote the paper. performed infrared analysis, surface analysis, and wrote the paper. Lyudmila Lyoshina: designed and performed antibacterial experiments. Oksana Tarasyuk: prepared polymer composites and performed spectrophotometric studies. Olga Bulko: performed antibacterial experiments. Oleg Dzhuzha: performed elemental analysis and surface analysis. Tetiana
Cherniavska: performed thermal gravimetric analysis. Valeriy Kremenitsky: performed SEM and EDS analysis. Larisa Kobrina: performed DSC analysis. Sergii Riabov: conceived and designed the experiments, and analyzed the data.

\section{Declaration of competing interest}

The authors declare that they have no known competing financial interests or personal relationships that could have appeared to influence the work reported in this paper.

\section{References}

[1] J.O. Akindoyo, M.D.H. Beg, S. Ghazali, M.R. Islam, N. Jeyaratnam, A.R. Yuvaraj, Polyurethane types, synthesis and applications - a review, RSC Adv. 6 (2016) 114453-114482, https://doi.org/10.1039/C6RA14525F.

[2] J.I. Wright, Using Polyurethanes in Medical Applications, 2006. https://www. mddionline.com/using-polyurethanes-medical-applications. (Accessed 1 March 2006).

[3] F.J. Davis, G.R. Mitchell, Polyurethane based materials with applications in medical devices, in: P. Bártolo, B. Bidanda (Eds.), Bio-Materials and Prototyping Applications in Medicine, Springer, New York, 2007, pp. 27-48. https://www.sp ringer.com/gp/book/9780387476827.

[4] P. Kaali, E. Strömberg, S. Karlsson, A.N. Laskovski, Prevention of biofilm associated infections and degradation of polymeric materials used in biomedical applications, in: Biomedical Engineering, Trends in Material Science, In Tech, Rijeka, 2011, pp. 513-541, https://doi.org/10.5772/12983 (Chapter 22).

[5] H. Kumon, H. Hashimoto, M. Nishimura, K. Monden, N. Ono, Catheter-associated urinary tract infections: impact of catheter materials on their management, Int. J. Antimicrob. Agents 17 (2011) 311-316, https://doi.org/10.1016/s0924-8579(00) 00360-5.

[6] J.W. Costerton, S.P. Stewart, E.P. Greenberg, Bacterial biofilms: a common cause of persistent infections, Science 284 (1999) 1318-1322, https://doi.org/10.1126/ science.284.5418.1318.

[7] R. Donlan, Biofilm formation: a clinically relevant microbiological process, Clin. Infect. Dis. 33 (2001) 1387-1392, https://doi.org/10.1086/322972.

[8] I. Keren, N. Kaldalu, A. Spoering, Y. Wang, K. Lewis, Persister cells and tolerance to antimicrobials, FEMS Microbiol. Lett. 230 (2004) 13-18, https://doi.org/10.1016/ S0378-1097(03)00856-5.

[9] W.L. Hinrichs, E.J. Lommen, C.R. Wildevuur, J. Feijen, Fabrication and characterization of an asymmetric polyurethane membrane for use as a wound dressing, J. Appl. Biomater. 3 (1992) 287-303, https://doi.org/10.1002/ jab.770030408.

[10] S.M. Lee, I.K. Park, Y.S. Kim, H.J. Kim, H. Moon, S. Mueller, Y.I. Jeong, Physical, morphological, and wound healing properties of a polyurethane foam-film dressing, Biomater. Res. 20 (2016) 15, https://doi.org/10.1186/s40824-016-00635.

[11] R. Edwards, K.G. Harding, Bacteria and wound healing, Curr. Opin. Infect. Dis. 17 (2004) 91-96, https://doi.org/10.1097/00001432-200404000-00004.

[12] D. Nichols, Biocides in plastics, in: Rapra Review Reports 15, iSmithers Rapra Publishing, Akron OH, 2004. No. 180,, https://epdf.pub/biocides-in-plastics -rapra-review-report-180.html.

[13] Q.L. Feng, J. Wu, G.Q. Chen, F.Z. Cui, T.N. Kim, J.O. Kim, A mechanistic study of the antibacterial effect of silver ions on Escherichia coli and Staphylococcus aureus, J. Biomed. Mater. Res. 52 (2000) 662-668, https://doi.org/10.1002/10974636(20001215)52:4<662::aid-jbm10>3.0.co;2-3.

[14] J.W. Beam, Topical silver for infected wounds, J. Athl. Train. 44 (2009) 531-533, https://doi.org/10.4085/1062-6050-44.5.531.

[15] N. Rabin, Y. Zheng, C. Opoku-Temeng, Y. Du, E. Bonsu, H.O. Sintim, Agents that inhibits bacterial biofilm formation, Future Med. Chem. 7 (2015) 647-671, https://doi.org/10.4155/fmc.15.7. 
[16] M. Villani, R. Consonni, M. Canetti, F. Bertoglio, S. Iervese, G. Bruni, L. Visai, S. Iannace, F. Bertini, Polyurethane-based composites: effects of antibacterial fillers on the physical-mechanical behavior of thermoplastic polyurethanes, Polymers 12 (2020) 362, https://doi.org/10.3390/polym12020362.

[17] X. Zhang, H. Su, Y. Zhao, T. Tan, Antimicrobial activities of hydrophylic polyurethane/titanium dioxide complex film under visible light irradiation, J. Photochem. Photobiol., A 199 (2008) 123-129, https://doi.org/10.1016/j. jphotochem.2008.05.002.

[18] D. Paul, S. Paul, N. Roohpour, M. Wilks, P. Vadgama, Antimicrobial, mechanical and thermal studies of silver particle-loaded polyurethane, J. Funct. Biomater. 4 (2013) 358-375, https://doi.org/10.3390/jfb4040358.

[19] Y. Savelyev, A. Gonchar, B. Movchan, A. Gornostay, S. Vozianov, A. Rudenko, R. Rozhnova, T. Travinskaya, Antibacterial polyurethane materials with silver and copper nanoparticles, Mater. Today Proceed. 4 (2017) 87-94, https://doi.org/ 10.1016/j.matpr.2017.01.196.

[20] B. Cabal, D. Sevillano, E. Fernández-García, L. Alou, M. Suárez, N. González, J. S. Moya, R. Torrecillas, Bactericidal ZnO glass-flled thermoplastic polyurethane and polydimethyl siloxane composites to inhibit bioflm-associated infections, Sci. Rep. 9 (2019) 2762, https://doi.org/10.1038/s41598-019-39324-w.

[21] K. Ziegler, R. Görl, J. Effing, J. Ellermann, M. Mappes, S. Otten, H. Kapp, P. Zoellner, D. Spaeth, H. Smola, Reduced cellular toxicity of new silver-containing antimicrobial dressing and clinical performance in non-healing wounds, Skin Pharmacol, Physiol. 19 (2006) 140-146, https://doi.org/10.1159/000092594.

[22] S.M. Lee, K. Park, Y.S. Kim, H.J. Kim, H. Moon, S. Mueller, H. Arumugam, Y.I. Leong, Superior absorption and retention properties of foam-film silver dressing versus other commercially available silver dressing, Biomater. Res. 20 (2016) 22, https://doi.org/10.1186/s40824-016-0069-z.

[23] S.B. Zou, W.Y. Yoon, S.K. Han, S.H. Jeong, Z.J. Cui, W.K. Kim, Cytotoxicity of silver dressings on diabetic fibroblasts, Int. Wound J. 10 (2013) 306-312, https://doi. org /10.1111/j.1742-481X.2012.00977.x.

[24] S.L. Percival, P.G. Bowler, D. Russell, Bacterial resistance to silver in wound care, J. Hosp. Infect. 60 (2005) 1-7, https://doi.org/10.1016/j.jhin.2004.11.014.

[25] A.T. Hendry, I.O. Stewart, Silver resistant Enterobacteriaceae from hospital patients, Can. J. Microbiol. 25 (1979) 915-921, https://doi.org/10.1139/m79-136.

[26] B. Walder, D. Pittet, M.R. Tramer, Prevention of bloodstream infections with central venous catheters treated with anti-infective agents depends on catheter type and insertion time: evidence from a meta-analysis, Infect. Control Hosp. Epidemiol. 23 (2002) 748-756, https://doi.org/10.1086/502005.

[27] H. Wang, H. Tong, H. Liu, Y. Wang, R. Wang, H. Gao, P. Yu, Y. Lv, S. Chen, G. Wang, M. Liu, Y. Li, K. Yu, C. Wang, Effectiveness of antimicrobial-coated central venous catheters for preventing catheter-related blood-stream infections with the implementation of bundles: a systematic review and network metaanalysis, Ann. Intensive Care 8 (2018) 71, https://doi.org/10.1186/s13613-0180416-4.

[28] R.A. Cooper, Iodine revisited, Int. Wound J. 4 (2007) 124-137, https://doi.org/ 10.1111/j.1742-481X.2007.00314.x.

[29] K. Jayaraja Kumar, C. Hemanth Kumar Reddy, V. Gunashakaran, Y. Ramesh, P. Kalayan Babu, N. Pawan Narasimha, A. Venkatewarulu, P. Lakshmikanth Reddy, Application of broad spectrum antiseptic povidone iodine as powerful action: a review, J. Pharmaceut. Sci. Technol. 1 (2009) 48-58. http://www.onlinephar macytech.info/docs/vol1issue2/JPST09-01-02-01.pdf.

[30] P.L. Bigliardi, S.A.L. Alsagoff, H.Y. El-Kafrawi, J.-K. Pyon, C.T.C. Wa, M.A. Villa, Povidone iodine in wound healing: a review of current concepts and practices, Int. J. Surg. 44 (2017) 260-268, https://doi.org/10.1016/j.ijsu.2017.06.073.

[31] M. Karakelle, C. David Benson, R.A. Taller, M.-S. Lee, M.A. Khan, Polyurethane sponge having rapid iodine release, US Patent (1994) 5302392.

[32] J.A. Jung, S.K. Han, S.H. Jeong, E.S. Dhong, K.G. Park, W.K. Kim, In vitro evaluation of Betafoam, a new polyurethane foam dressing, Adv. Skin Wound Care 30 (2017) 262-271, https://doi.org/10.1097/01.ASW.0000513090.75457.f4.

[33] J.W. Lee, K.Y. Song, Evaluation of a polyurethane foam dressing impregnated with $3 \%$ povidone-iodine (Betafoam) in a rat wound model, Ann. Surg. Treat. Res. 94 (2018) 1-7, https://doi.org/10.4174/astr.2018.94.1.1.

[34] D.O. Lowe, S.R. Knowles, E.A. Weber, C.J. Railton, N.H. Shear, Povidone-iodineinduced burn: case report and review of the literature, Pharmacotherapy 26 (2006) 1641-1645, https://doi.org/10.1592/phco.26.11.1641.

[35] I. Levin, J. Amer-Alshiek, A. Avni, J.B. Lessing, A. Satel, B. Almog, Chlorhexidine and alcohol versus povidone-iodine for antisepsis in gynecological surgery, J. Womens Health (Larchmt) 20 (2011) 321-324, https://doi.org/10.1089/ jwh.2010.2391.

[36] K. Moore, D. Gray, Using PHMB antimicrobial to prevent wound infection, Wounds UK 3 (2007) 96-102. https://www.woundsme.com/uploads/resources/content 9136.pdf.

[37] K. Kaehn, Polyhexadine: a safe and highly effective biocide, Skin Pharmacol. Physiol. 23 (2010) 7-16, https://doi.org/10.1159/000318237.

[38] M.K. Oulè, R. Azinwi, A.M. Bernier, T. Kablan, A.M. Maupertuis, S. Mauler, R. Koffi- Nevry, K. Dembèlè, L. Forbes, L. Diop, Polyhexamethylene guanidine hydrochloride-based disinfectant: a novel tool to fight meticillin-resistant Staphylococcus aureus and nosocomial infections, J. Med. Microbiol. 57 (2008) 1523-1528, https://doi.org/10.1099/jmm.0.2008/003350-0.
[39] Z. Zhou, D. Wei, Y. Guan, A. Zheng, J.-J. Zhong, Extensive in vitro activity of guanidine hydrochloride polymer analogs against antibiotics-resistant clinically isolated strains, Mater. Sci. Eng. 31 (2011) 1836-1843, https://doi.org/10.1016/j. msec.2011.08.015.

[40] H. Choi, K.-J. Kim, D.J. Lee, Antifungal activity of the cationic antimicrobial polymer-polyhexamethylene guanidine hydrochloride and its mode of action, Fungal Biol. 121 (2017) 53-60, https://doi.org/10.1016/j.funbio.2016.09.001.

[41] Y. Zhang, J. Jiang, Y. Chen, Synthesis and antimicrobial activity of polymeric guanidine and biguanidine salts, Polymer 40 (1999) 6189-6198, https://doi.org/ 10.1016/S0032-3861(98)00828-3.

[42] A. Worsley, K. Vassileva, J. Tsui, W. Song, L. Good, Polyhexamethylene biguanide: polyurethane blend nanofibrous membranes for wound infections control, Polymers 11 (2019) 915, https://doi.org/10.3390/polym11050915.

[43] A. Doroshenko, N. Gorchakova, G. Zaychenko, Effect of a nanodispersion silica composite with polyhexamethylene guanidine hydrochloride on immunological indicators and indicators of oxidation and antioxidant homeostasis in rats with thermal burn, Science: Pharmaceut. Sci. 4 (2019) 45-52, https://doi.org/ 10.15587/2519-4852.2019.178951.

[44] T.M. Kamenieva, O.P. Tarasyuk, K. Yu Derevianko, O.A. Aksenovska, O. V. Shybyryn, L.O. Metelytsia, S.P. Rogalsky, Antioxidant activity of polymeric biocide polyhexamethylene guanidine hydrochloride, Catalysis and Petrochemistry 30 (2020) 73-82, https://doi.org/10.15407/kataliz2020.30.073.

[45] I.J. Asiedu-Gyekye, S.A. Mahmood, C. Awortwe, A.K. Nyarko, A preliminary safety evaluation of polyhexamethylene guanidine, Int. J. Toxicol. 33 (2014) 523-531, https://doi.org/10.1177/1091581814553036.

[46] I.J. Asiedu-Gyekye, S.A. Mahmood, C. Awortwe, A.K. Nyarko, Toxicological assessment of polyhexamethylene biguanide for water treatment, Interdiscipl. Toxicol. 8 (2015) 193-202, https://doi.org/10.1515/intox-2015-0029.

[47] F.G.G. Dias, L. de Freitas Pereira, R.L. Tame Parreira, R.C. Sola Veneziani, T. C. Bianchi, V.F.N. de Paula Fontes, M. de Carlos Galvani, D. Dal Picolo Cerce, C.H. G. Martins, F. Rinaldi-Neto, N.H. Ferreira, L.H.D. da Silva, L.T. Souza de Oliveira, T.R. Esperandim, F.A. de Sousa, S.R. Ambrósio, D.C. Tavares, Evaluation of the antiseptic and wound healing potential of polyhexamethylene guanidine hydrochloride as well as its toxic effects, Eur. J. Pharmaceut. Sci. (2021) 105739, https://doi.org/10.1016/j.ejps.2021.105739.

[48] G.F. de Paula, G.I. Netto, L.H.C. Mattoso, Physical and chemical characterization of poly(hexamethylene biguanide) hydrochloride, Polymers 3 (2011) 928-941, https://doi.org/10.3390/polym3020928.

[49] European Commission, Scientific Committee on Consumer Safety, Opinion on the Safety of Poly(hexamethylene) Biguanide Hydrochloride (PHMB), July 2015. http s://ec.europa.eu/health/scientific_committees/consumer_safety/docs/sccs_o_157. pdf.

[50] S. Rogalsky, J.-F. Bardeau, H. Wu, L. Lyoshina, O. Bulko, O. Tarasyuk, S. Makhno, T. Cherniavska, Y. Kyselov, J.H. Koo, Structural, thermal and antibacterial properties of polyamide 11/polymeric biocide polyhexamethylene guanidine dodecylbenzenesulfonate composites, J. Mater. Sci. 51 (2016) 7716-7730, https:// doi.org/10.1007/s10853-016-0054-x.

[51] M. Sahraro, H. Yeganeh, M. Sorayya, Guanidine hydrochloride embedded polyurethanes as antimicrobial and absorptive wound dressing membranes with promising cytocompatibility, Mater. Sci. Eng. C 59 (2016) 1025-1037, https://doi. org/10.1016/j.msec.2015.11.038.

[52] A.W. Bauer, W.M.M. Kirby, J.C. Sherris, A.M. Turck, Antibiotic susceptibility testing by a standardized single disk method, Am. J. Clin. Pathol. 45 (1966) 493-496, https://doi.org/10.1093/ajcp/45.4 ts.493.

[53] ISO 22196:2011, Measurement of antibacterial activity on plastics and other nonporous surfaces (2011-08). https://www.iso.org/standard/54431.html.

[54] M. Martí, B. Frígols, A. Serrano-Aroca, Antimicrobial characterization of advanced materials for bioengineering applications, JoVE 138 (2018), e57710, https://doi. org/10.3791/57710.

[55] C. Wilhelm, A. Rivaton, J.-L. Gardette, Infrared analysis of the photochemical behaviour of segmented polyurethanes, Polymer 39 (1998) 1223-1232, https:// doi.org/10.1016/S0032-3861(97)00353-4.

[56] S.J. McCarthy, G.F. Meijs, N. Mitchell, P.A. Gunatillake, G. Heath, A. Brandwood, K. Schindhelm, In-vivo degradation of polyurethanes: transmission-FTIR microscopic characterization of polyurethanes sectioned by cryomicrotomy, Biomaterials 18 (1997) 1387-1409, https://doi.org/10.1016/S0142-9612(97) 00083-5.

[57] F. Șen, S. Madakbaş, E. Baștürk, M.V. Kahraman, Morphology and mechanical properties of thermoplastic polyurethane/colemanite composites, Polymer 41 (2017) 1019-1026, https://doi.org/10.7317/pk.2017.41.6.1019.

[58] D. Wei, R. Zhou, Y. Guan, A. Zheng, Y. Zhang, Investigation on the reaction between polyhexamethylene guanidine hydrochloride oligomer and glycidyl methacrylate, J. Appl. Polym. Sci. 127 (2013) 666-674, https://doi.org/10.1002/ app.37849.

[59] Y. Li, X. Huang, L. Shen, J. Zhao, Explore the applications of nano-silver polyurethane skin wound dressing, Surg. Case Rep. 3 (2020), https://doi.org/ 10.31487/j.SCR.2020.06.22, 4-3. 